\title{
The role of verb tense and verb aspect in the foregrounding of information during reading
}

\author{
MANUEL CARREIRAS \\ Universidad de La Laguna, Tenerife, Spain \\ NÚRIA CARRIEDO \\ Universidad de Salamanca, Salamanca, Spain \\ MARÍA ANGELES ALONSO \\ Universidad de La Laguna, Tenerife, Spain \\ and \\ ANGEL FERNÁNDEZ \\ Universidad de Salamanca, Salamanca, Spain
}

\begin{abstract}
In three experiments, we explored the role of verb tense and verb aspect in subjects' construction of mental models while reading. In the first and second experiments, subjects read paragraphs in which verb tense was manipulated to assign current and past attributes (job descriptions) to a main character. The results showed that on-line accessibility was faster for current attributes. The results of the third experiment showed that verb aspect manipulations regarding character actions affect the speed at which the characters are available for recognition.
\end{abstract}

There is a fairly broad consensus that, during text comprehension, subjects represent not only the surface structure of the text but also the meaning of the text. Subjects construct a discourse model that represents the entities and events evoked by the discourse and the relationships among them (Garnham, 1981; Johnson-Laird, 1983; Sanford \& Garrod, 1981; van Dijk \& Kintsch, 1983). Apart from this primary characteristic, some other features have been attributed to mental models. For instance, it is assumed that mental models contain tokens whose number corresponds to the number of entities of the real world to be represented, and that mental models capture different kinds of relationships between these entities. They are also dynamic representations, which are constructed on line; they can be updated with incoming information.

Some empirical work has confirmed the idea that mental models preserve some physical properties of space even when space was not perceived but was constructed from a verbal description (Bryant, Tversky, \& Franklin, 1992; Franklin \& Tversky, 1990; Mani \& Johnson-Laird, 1982; Taylor \& Tversky, 1992). Some other investigations also suggest that there is an incremental updating of the

This research was supported by Grant PB93-0562 from the DGICYT to the University of La Laguna and by Grant PB93-0617 from the DGICYT to the University of Salamanca. Some parts of this research were presented in November 1994, at the annual meeting of the Psychonomic Society, St. Louis. The authors are indebted to Nancy Franklin, Alan Garnham, Art Glenberg, Jane Oakhill, Kathryn Spoehr, Victor Villa, Rolf Zwaan, and an anonymous reviewer for helpful comments. Correspondence should be addressed to M. Carreiras, Departamento de Psicología Cognitiva, Universidad de La Laguna, 38205 Tenerife, Spain (e-mail: mcarreiras@ull.es). representation on the basis of the present and past input, so that the resulting representation, at a given moment, guides the interpretation of subsequent input (Carreiras, Garnham, Oakhill, \& Cain, 1996; De Vega, 1995; Morrow, Bower, \& Greenspan, 1989; Rinck \& Bower, 1995). Furthermore, the tokens and events represented in the mental model are organized in a way such that their accessibility changes over time. In general, the accessibility of a given token is determined not only by how it is introduced into the mental model but also by subsequent references to it, by its importance to the main sequence of events in the narrative, and by its relation to the main character of a narrative, around which situation models tend to be organized. For instance, Glenberg, Meyer, and Lindem (1987) found that objects mentioned in a narrative remain foregrounded and available as a function of their spatial proximity to the main character of the story. Morrow, Greenspan, and Bower (1987) replicated this effect, finding that objects earlier described as being in the same room as the main character were more accessible to readers than were objects in another room. Morrow et al. (1989) extended such findings by showing that objects corresponding to an unmentioned room in the pathway between two rooms were more accessible than were objects corresponding to a mentioned but irrelevant room. Thus, readers' focus of attention on the protagonist makes the information related to the protagonist more accessible.

Most of the research on mental models has explored the representation of spatial relations. The study of spatial relations has been useful in demonstrating that a propositional representation cannot fully account for the product of text comprehension. However, mental models 
should also be capable of elucidating how other types of information are comprehended. In fact, subjects also represent fictional characters' emotional states, even when emotional words are not explicitly mentioned in the text (Gernsbacher, Goldsmith, \& Robertson, 1992; Gernsbacher \& Robertson, 1992) and the social stereotypes associated with characters when they are described by role names (Carreiras et al., 1996). In addition, some investigations have suggested that subjects capture the temporal structure described in a text by representing the duration of familiar events (e.g., Anderson, Garrod, \& Sanford, 1983). In particular, Anderson et al. showed that the temporal properties of the situations that narratives describe determine the character that readers think a pronoun refers back to, influence reading times, and produce changes in the on-line accessibility of characters in the text. When readers encounter in a text temporal phrases (e.g., five hours later) that exceed the typical duration of an activity (e.g., five hours later exceeds the length of a restaurant meal), they slow down their reading speed and have difficulty remembering a previously mentioned character bound to that activity (e.g., a waiter), relative to when they encounter temporal phrases that do not exceed the typical duration of such activity (e.g., five minutes later). More recently, Zwaan and colleages (Zwaan, 1996; Zwaan, Langston, \& Graesser, 1995; Zwaan, Magliano, \& Graesser, 1995) demonstrated that readers use temporal information to construct situation models during narrative comprehension by showing that narrative time shifts produce an increase in processing load during comprehension, as measured by reading times and response latencies. Specifically, Zwaan, Magliano, and Graesser (1995) obtained such evidence employing multiple regression analyses on sentence reading times for naturalistic stories. Zwaan (1996) introduced time shifts in narratives by using temporal adverbials (e.g., a moment later/an hour later/a day later) and measured both reading time for the sentences containing them and response time (RT) to probe words presented for recognition immediately after the critical sentence. In both studies, subjects were sensitive to temporal discontinuities while reading in order to build a representation of a text, showing evidence of difficulties during the comprehension process. The present paper examines how time relations between a character and a job description or between two characters affect their status in the representation.

Mental models represent states of affairs of the real world, but they are not necessarily pictures of the world. In fact, they make use of working memory resources, so they are not complete representations; they do not incorporate all the available information. More importantly, they embody a selective activation mechanism. As stated before, the same information is not continuously activated over time. In fact, some entities become more activated than others do as the discourse unfolds. In other words, some entities are foregrounded in the reader's attentional focus, whereas others are placed in the background. Foregrounding is dynamic, as the attentional focus moves from one token to others in the course of comprehension. The change or maintenance of focus is governed by nonlinguistic knowledge and by linguistic information. The entities in the foreground will be those tied to the main sequence of events of the narrative, where main characters perform their actions. So, main characters will be foregrounded in the reader's model, as will be tokens spatially associated with them. For instance, objects attached to main characters tend to be more accessible than are objects separated from main characters (Glenberg et al., 1987), and objects related to main characters goals are more accessible regardless of how recently they were mentioned in the text (Morrow et al., 1989). Focusing depends also on some grammatical cues provided by the text, such as animacy, word order, word repetition, anaphoric devices, tense-aspect systems of the verb, and so on (Givon, 1992; Hopper, 1979; Morrow, 1985a). For instance, main characters, usually introduced into the narrative by proper names, are more prominent and accessible than are secondary characters, introduced by role names (Anderson et al., 1983; Morrow, 1985b). Furthermore, first-mentioned characters are more accessible than are second-mentioned characters (Carreiras, Gernsbacher, \& Villa, 1995; Gernsbacher \& Hargreaves, 1988).

Thus, mental models, which capture the spatial structure of events, influence the process of comprehension by controlling what information is maintained highly activated or foregrounded. However, mental models contain more than spatial information, as described earlier, and foregrounding does not seem to be restricted to information spatially associated with or dissociated from the main character. Fernández and Saiz (1989; Saiz \& Fernández, 1995) showed that descriptive traits that were associated with or dissociated from the main character by means of social consensus statements about the main character (e.g., almost everybody considers ... vs. almost nobody considers ...) produced different latency times in a probe recognition task. Associated adjectives were recognized faster than were dissociated adjectives. Therefore, if mental models are multidimensional representations, and both spatial and social information show a foregrounding effect, it is reasonable to assume that a foregrounding mechanism operates in relation to the temporal dimension. One main goal of the present study was to investigate whether or not readers are sensitive to foregrounding effects in the temporal domain.

Foregrounding seems to be sensitive to some grammatical markers, such as tense-aspect systems of the verb. Tense-aspect systems of the verb are devices that may be used to guide the reader through the text, by establishing temporal relations between events in the discourse. For instance, tense-aspect markers may signal happenings, states, or events that are sequential or nonsequential. They can also indicate that events occur successively or simultaneously. So, tense-aspect markers determine events to be temporally consistent or inconsistent with the stream of the discourse. In fact, one of the 
typical properties of background is the distortion or break of the time frame of the text, because secondary events do not have to be concurrent with the main events but may be part of the previous narrated event. In contrast, foreground requires a conventional description of successive events (Hopper, 1979).

Tense and aspect are two major grammatical mechanisms for expressing temporal relations (e.g., Comrie, 1976,1985 ). Temporal information given lexically must coordinate with temporal information given by tense and aspect markers. Linguists usually distinguish between tense and aspect when describing the grammar of temporal relations. In principle, the distinction is clear enough. Tense has to do with grammatical devices, whereby the time of occurrence of a referent event is related to the time of utterance. Aspect has to do with the time course of the referent event itself, independent of its time of occurrence. In other words, aspect is the way that an event is distributed through the time frame in which the event occurs. Consider the following sentences.

\section{John walks.}

2. John walked.

\section{John was walking.}

Tense indicates time in terms of the present, the past, and the future, as it occurs in Sentences 1 and 2 . Along a time line, the past tense can be used to refer to events that take place in an undifferentiated temporal extent, moving away from the present moment into the already known or completed, whereas the present tense can be used to refer to events that take place in an area of the time line simultaneous with the moment of speech. Thus, tense is deictic because it concerns the relative ordering of events in time and, thus, relies on the anchoring of an event in relation to a temporal reference point; however, aspect is not deictic. Aspect is generally understood as the nondeictic structure of an event, relative to tense. Sentences 2 and 3 represent the same active motion event "walk" as occurring in the past, but they differ in the temporal properties that they ascribe to the event within the past time frame. Sentence 2, which simply expresses the motion event as a completed act, says nothing about the internal composition of the event, unlike Sentence 3. In Sentence 3 , the event is necessarily extended or stretched into a continuous event, even though it is still relegated to the past.

However, in spite of this theoretical distinction between tense and aspect, when this distinction is imposed on natural languages, the hypothetical independence of tense and aspect is less apparent. In actual usage, the two systems merge-for example, in the present perfect (e.g., John has walked to school). Therefore, we will not make any processing distinction between tense and aspect, treating both as grammatical resources to mark the temporal organization of a narrative. We simply will take advantage of both devices, tense and aspect, to produce a temporal association or dissociation between two pieces of information in the texts.
In this paper, we describe three experiments, carried out using the same procedure as that of Glenberg et al. (1987), to test whether changes of focusing could be observed by changing the temporal status of the relationships between two pieces of information described in the text. These two pieces of information were the names of main characters and job descriptions applied to the characters in Experiments 1 and 2 and between the names of two characters in Experiment 3. We expected to observe in the temporal dimension the same associate-dissociate effect that was observed in the spatial dimension. In particular, we expected that when the text presented a relationship as currently holding, an association between the character and the job description (Experiments 1 and 2) or between the two characters (Experiment 3) would be likely to persist in the mental representation. In contrast, when the text presented a relationship as belonging to the past, no such persistence would be expected. We tested this idea in three experiments, in which the status (present or past) of a description of the character was manipulated by a change in verb tense (present or past) and the accompanying temporal adverb (Experiments 1 and 2) and by a single change in verb aspect (Experiment 3 ).

\section{EXPERIMENT 1}

In Experiment 1, subjects read paragraphs in which a job description was presented as either currently applying to a main character or not currently applying to that character. We assumed that when a job description is presented as currently applying to a central character, the mental model of the text would be likely to incorporate a relationship between the token representing the character and the token representing the job description. On the other hand, when a job description is presented as applying to a person in the past, the mental model of the text would not be likely to incorporate such a relationship between the person token and the job description token. Our prediction was that job descriptions presented in the present tense, as current descriptions of the main character, and therefore associated with the character in the mental model representation, would remain foregrounded, and they would be recognized more quickly than would job descriptions presented in the past tense, as past descriptions of the character, and therefore currently dissociated from the character.

Each entity in the discourse model has some degree of accessibility relative to the other entities. This degree of accessibility depends, among other things, on how the entities are introduced in the text. For instance, characters described by proper names are usually more accessible than are characters introduced by role names (Sanford, Moar, \& Garrod, 1988). But, as we have seen, accessibility changes as the text develops. Readers update their representation, and it is still unclear which is the optimal probe point to observe foregrounding effects. Thus, Glenberg et al. (1987) found the association-dissociation effect after a one-sentence delay, whereas Fernández and Saiz (1989), using the same procedure but different ma- 
terials, found a similar association-dissociation effect after a two-sentence delay. Therefore, for pragmatic reasons, to maximize our chances of obtaining evidence for the process of constructing and updating a situation model during narrative comprehension, we included three delay test points between the end of the critical sentence and the presentation of the target word.

\section{Method}

Subjects. The subjects were 32 undergraduate students from the University of Salamanca who participated voluntarily in the experiment.

Design and Materials. We constructed a total of 80 paragraphs, 8 of which were for practice. Each paragraph consisted of four text segments, and each segment contained one sentence, with the exception of the second segment, which contained two sentences (for an example, see Table 1). The first text segment of each paragraph was a setting sentence that introduced a person who was to be the main character in that paragraph. The next segment contained two sentences. The second of these two sentences was the critical sentence, which always stated a relationship between the character and a job description. In the associated condition, the critical sentence stated that the job description currently applied to the main character. In the dissociated condition, the critical sentence stated that the job description applied to the main character in the past. The third and fourth segments were used as fillers for a delayed word recognition test; each contained a single sentence. The third and fourth segments never referred to the job description; the main character was kept foregrounded by descriptions of her or his actions. A content question requiring a "yes" or "no" answer was prepared for each paragraph.

Procedure. The materials were presented visually on the screen of a Macintosh (SE) computer. A custom-written Pascal computer program controlled presentation of stimuli and registered accuracy and timing of subject responses. The subjects participated individually. They listened to instructions read aloud by the experimenter, and they read 8 practice paragraphs and responded to words and questions presented on the computer screen. Next, they read the 72 paragraphs, 36 of which acted as experimental paragraphs and the other 36 as fillers for each subject. The assignment of a given passage as experimental or filler and the assignment to each experimental condition were randomly chosen by the program for each subject. After reading a segment, the subjects pressed the space bar on the computer keyboard to see the next segment in the paragraph. Once the critical sentence was read, pressing the space bar could result in the appearance of a test word, underlined and in the center of the screen. Depending on the type of trial, the test word appeared immediately after the critical sentence, after one filler sentence, or after two filler sentences. The subjects were instructed to respond

\section{Table 1}

Example of Paragraphs Used in Experiments 1 and 2

$\begin{array}{ll}\begin{array}{l}\text { Setting sentence } \\ \text { Critical } \\ \text { Associated }\end{array} & \begin{array}{l}\text { Marta is a 45-year-old woman, and she is un- } \\ \text { married. }\end{array} \\ \text { Dissociated } & \begin{array}{l}\text { She lives alone in a downtown apartment in } \\ \text { La Coruña. Now she works as an economist for } \\ \text { an international company. }\end{array} \\ & \begin{array}{l}\text { She lives alone in a downtown apartment in } \\ \text { La Coruna. Sometime in the past she worked as } \\ \text { an economist for an international company. }\end{array} \\ \text { Filler 1 } & \begin{array}{l}\text { She visits her parents on weekends. } \\ \text { She loves underwater photography, and she likes } \\ \text { to practice water sports. }\end{array} \\ \text { Test word } & \text { economist }\end{array}$

"yes" when they thought that the test word had appeared in the current paragraph and to respond "no" when they thought that the word had not appeared in the paragraph. After responding to the test word, the subjects continued to read the remaining sentences in the paragraph, if any. One fourth of the paragraphs were followed by a yes/no question, in order to induce reading for comprehension.

The experimental paragraphs always required a "yes" response to the test word that was the job description. Twelve of the filler paragraphs also required a "yes" response to the target that was the name of a city that appeared in the text. Finally, the other 24 fillers required "no" answers.

\section{Results and Discussion}

Of interest for the goals of the experiment were accuracy and RTs for correct responses when the word being tested was the job description used in the critical sentence either associated with or dissociated from the main character. The mean RTs for correct responses in each condition are shown in Figure 1. Three subjects failed to contribute two or more correct responses in at least one of the conditions, and their data were discarded before further analyses were performed. Individual scores that were more than 2.5 standard deviations $(S D \mathrm{~s})$ from the mean were eliminated (less than $5 \%$ of the data). All the data analyses were performed treating subjects and items as random factors. However, since each text was randomly chosen for each subject to be experimental or filler and to be assigned to a particular experimental condition, texts that did not have at least two observations in every experimental condition did not contribute to the items analysis. Therefore, only 51 of the 72 items were included in the items analysis.

Analyses of variance (ANOVAs) showed that the two main effects were reliable. Associated job descriptions were recognized more quickly than were dissociated job descriptions, but this difference was reliable only in the subjects analysis $\left[F 1(1,28)=11.57, M S_{\mathrm{e}}=9,471, p<\right.$ $\left..005 ; F 2(1,50)=2.79, M S_{\mathrm{e}}=39,544, p>.05\right]$. There was also a significant effect of delay of test $[F 1(2,56)=$ $46.43, M S_{\mathrm{e}}=25,329, p<.0001 ; F 2(2,100)=42.71$, $\left.M S_{\mathrm{e}}=39,544, p<.0001\right]$, reflecting slower RTs as delay increased. The interaction between type of sentence and delay of test was not reliable (both $F \mathrm{~s}<1$ ).

The mean error rates are presented in Table 2. In the analysis of the error rates, only delay was reliable. The greater the delay, the higher the error rate $[F(2,56)=15.31$, $\left.M S_{\mathrm{e}}=0.017, p<.0001\right]$. There was no significant effect of type of sentence $(F<1)$, and no significant interaction was found $\left[F(2,56)=1.78, M S_{\mathrm{e}}=0.012, p>.05\right]$. Importantly, this allowed us to reject the hypothesis that RT effects can be attributed to a speed-accuracy tradeoff

First, the main effect of delay, which was reliable both in RTs and in error rates, deserves some comment. The longer the delay, the harder it is to recognize whether the test word appeared in the text. Either the time between mentioning the test word in the text and presenting it for recognition or the simple fact that more words are incorporated in the representation with longer delays could account for the increase in RT and error rates. However, as we previously stated, studying the effect of delay was 


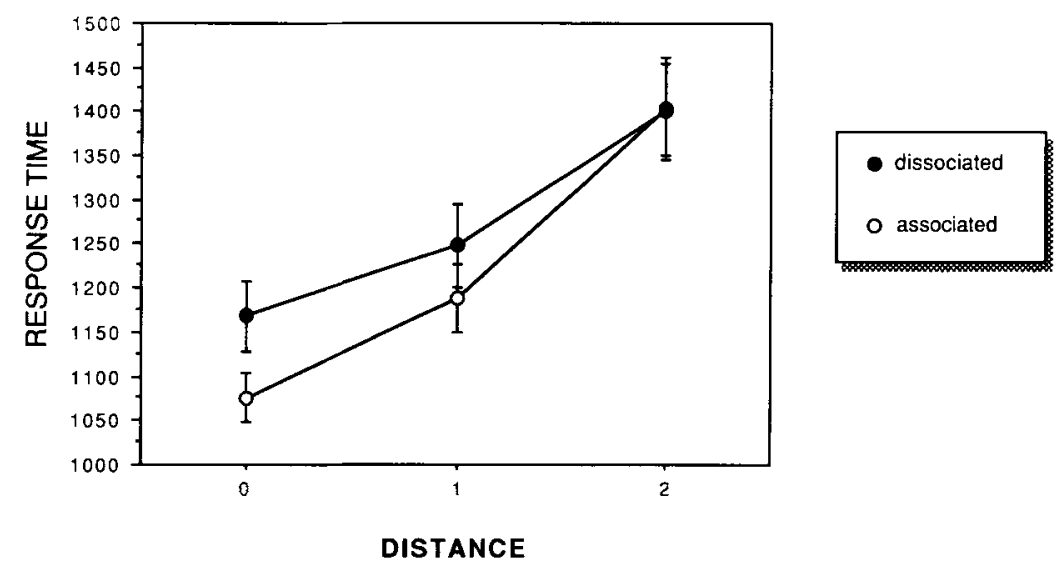

Figure 1. Mean RTs and standard error bars for associated and dissociated probe words at three delay tests in Experiment 1.

not the goal of this experiment, nor was it the goal of the next experiments, in which the different delays were used only in order to maximize the opportunity to show the foreground effect based on temporal relations. Therefore, unless they are of interest for some other reason, we will not comment on expected delay effects, such as the one we observed in this experiment.

On the other hand, the results concerning the associateddissociated effect suggest that the temporal status of the relations described in the text modulates the accessibility of the information in the mental model. It is easier to access a word from the text when this word is associated with the main character in the present, relative to when this same word is associated with the main character in the past.

These associated versus dissociated results suggest that spatial information is incorporated into the mental model of the text, as is temporal information (see Anderson et al., 1983; Zwaan, Langston, \& Graesser, 1995; Zwaan, Magliano, \& Graesser, 1995). However, some information in some of the paragraphs used in this experiment introduced spatial change in the main character's residence, as well as the temporal change (e.g., "[the character] just moved to Madrid. Before he/she worked as ..."). In such cases, the subjects could infer that the relation between the character and the job in the past was associated with another town. So, there could be a con-

Table 2

Percentage of Errors in Experiments 1, 2, and 3

\begin{tabular}{lccc}
\hline & \multicolumn{3}{c}{ Delay Test } \\
\cline { 2 - 3 } & Distance 0 & Distance 1 & Distance 2 \\
\hline Experiment 1 & & & \\
Associate & 0.5 & 11.6 & 13.4 \\
$\quad$ Dissociate & 2.9 & 7.6 & 16.4 \\
Experiment 2 & & & \\
Associate & 0.7 & 7.0 & 13.2 \\
$\quad$ Dissociate & 2.9 & 6.6 & 14 \\
Experiment 3 & & & \\
$\quad$ Past progressive & 30 & 3.2 & 5.5 \\
Past perfect & 3.9 & 4.4 & 4.4 \\
\hline
\end{tabular}

founding between spatial and temporal information. To overcome this problem, we modified such paragraphs, deleting all references to changes in the characters' locations, and we ran another experiment.

\section{EXPERIMENT 2}

Experiment 2 was a replication of Experiment 1 in which we tested the same hypothesis with the new texts, with references to spatial changes eliminated. We assumed that if we were able to replicate the findings of Experiment 1, we would be able to claim that temporal relations alone modulate foregrounding.

\section{Method}

Subjects. The subjects were 48 undergraduate students from the University of Salamanca who participated voluntarily in the experiment. None had participated in Experiment 1.

Design and Materials. In some texts that had been used in Experiment 1 , we made temporal changes in the main characters' occupations and changes in these characters' locations. In Experiment 2, all such texts were modified in order to exclude any spatial change. Apart from that, the design and materials were the same as those of Experiment 1.

Procedure. The procedure was similar to that of Experiment 1. The only change was in the assignment of the 72 paragraphs to different experimental conditions. Thirty-six paragraphs were designated as experimental items and the other 36 were designated as fillers for each subject. The assignment of each passage to one of the six experimental conditions was counterbalanced across subjects.

\section{Results and Discussion}

The mean correct RTs for the probe words associated with and dissociated from the character (i.e., the job description used in the critical sentence) after zero-, one-, and two-sentence delays are shown in Figure 2. The data of two subjects were discarded, because they failed to contribute two or more correct responses in at least one of the conditions. Individual scores that were more than $2.5 S D$ s from the mean were eliminated (less than $2 \%$ of the data). Again, all data analyses were performed treating subjects and items as random factors. Five of the 72 texts were not included in the item analysis because they 


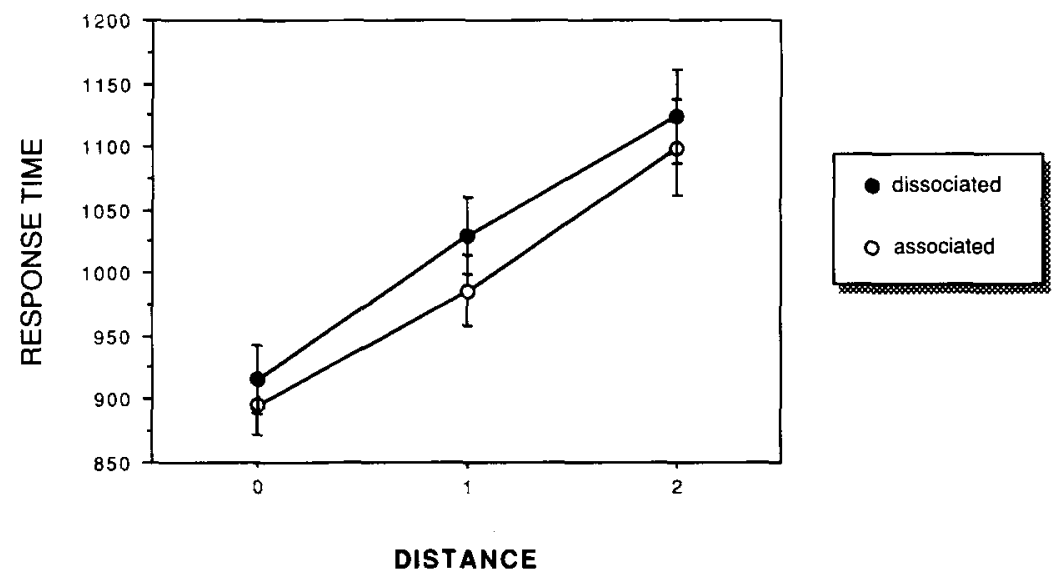

Figure 2. Mean RTs and standard error bars for associated and dissociated probe words at three delay tests in Experiment 2.

had less than two observations in at least one experimental condition.

ANOVAs showed that the main effect of association versus dissociation was reliable $\left[F 1(1,45)=6.93, M S_{\mathrm{e}}=\right.$ $60,054, p<.01 ; F 2(1,66)=6.63, M S_{\mathrm{e}}=17,490, p<$ $.05]$, as was the main effect of delay of test $[F 1(2,90)=$ $62.63, M S_{\mathrm{e}}=15,618, p<.0001 ; F 2(2,132)=58.62$, $\left.M S_{\mathrm{e}}=22,180, p<.0001\right]$. However, the interaction between the two factors was not reliable (both $F \mathrm{~s}<1$ ).

The mean error rates are presented in Table 2 . In the analysis of the error rates, only delay was reliable $[F(2,90)$ $\left.=23.28, M S_{\mathrm{e}}=0.014, p<.0001\right]$, showing that the error rate increased with the delay. Type of sentence did not have a significant effect $(F<1)$, and the interaction was not significant $(F<1)$, confirming that associatedissociate differences are not caused by a speed-accuracy tradeoff.

These results replicate those obtained in Experiment 1 and suggest that the temporal relation between a main character and a property of that character modulates the foregrounding of that property in the reader's mental model. When paragraphs that contained spatial changes were modified to leave only temporal relations available, a similar pattern of data was obtained.

\section{EXPERIMENT 3}

Situation models tend to be organized around a sequence of foreground events that constitute the plot of the narrative. In this main stream of the discourse, characters introduced by proper names play a major role. In Experiments 1 and 2, by manipulating the verb tense, we showed that information that was associated with the main character in the present was more activated than information associated in the past. Thus, temporal relations between main characters and job descriptions applied to them seem to be preserved and updated in the mental model of the text.

In Experiment 3, we wanted to investigate whether or not readers keep track of temporal relations between two characters, where the temporal information is conveyed by verb aspect markers. The subjects read short paragraphs that contained two characters introduced by their proper names (for an example, see Table 3). The actions performed by the characters occurred simultaneously or at different times, depending on the aspect of the past tense verb (past progressive or past perfect) used in the description of the target character's actions. When the actions were described using the past progressive, both characters would be in the focus of a scenario-like representation, and the target character would be easily accessed. On the other hand, the use of the past perfect to describe the actions of the target character would very likely place that character in the background, outside the focus of the current scenario representation, rendering it less accessible for further processing. Therefore, we predicted that the target character should be recognized faster when it was in focus than when that character was in the background.

\section{Method}

Subjects. The subjects were 60 undergraduate students from the University of La Laguna who received course credit for their participation.

Design and Materials. We constructed 72 paragraphs, of which 36 were experimental and 36 fillers, and 5 additional ones for practice (see Table 3 for an example). Each paragraph was displayed in six segments. The first two segments introduced two characters by their proper names, one male and one female. In the next two segments, each of these characters performed an action. The two actions either did or did not occur at the same time in the common scenario. The third segment described an action of the target character using the past progressive in half of the paragraphs and the past per-

Table 3 Example of Paragraphs Used in Experiment 3

1. John works as a waiter in a restaurant

2. Mary eats there every day.

3a. John was finishing his shift

3b. John had finished his shift

4. when Mary arrived at the restaurant.

5 . She asked for the dish of the day.

6. She read the newspaper while waiting for the food.

Test word John 
fect in the other half. The fourth segment completed the previous sentence by describing the arrival of the other character in the scenario. The fifth and the sixth segments were filler sentences for a delayed word recognition test. They never referred to the target character but always referred to the anchor character introduced in the second sentence. In each paragraph, the participants were described by their proper names. Only familiar proper names were used. For each paragraph, two proper names of different genders, one female and one male, and of the same length in number of letters were used. The target word for the experimental paragraphs was always the name of the character included in the third display whose action could be described either with a past progressive or a past perfect form of the verb. The filler texts were similar to the experimental ones. The only difference between the two types of paragraphs was that, in the experimental paragraphs, the test word required a positive response because it had appeared in the text, whereas this was not always the case for the fillers. In 12 of the filler paragraphs, the test word required a positive response because it was a noun that appeared in the text. In the rest of the fillers, the probe word required a negative response because it was a proper name or a noun that did not appear in the text.

There were six lists of materials so that each experimental text occurred in each of the six experimental conditions. The assignment of each experimental passage to one of the six conditions was counterbalanced across subjects.

Procedure. The subjects were tested individually in a small quiet room. Each subject read the 36 experimental texts intermixed randomly with each other and with 36 fillers. The experiment was controlled on line by an IBM-compatible computer. The subjects' task was to read the texts at their own pace and to respond to the test words and to the questions as quickly and accurately as possible. Before the presentation of the experimental materials, there were 5 practice trials whose primary purpose was to familiarize the subjects with the procedure. Next, they started reading the experimental paragraphs. Each trial was begun when the subject pressed the space bar, and the first segment of the paragraph was displayed. After reading it, the subject again pressed the space bar to read the next segment, and so on. When the fourth segment was read, which completed the critical sentence, pressing the space bar could result in the appearance of a test word, in uppercase letters in the center of the screen. Depending on the type of trial, the test word appeared immediately after the fourth segment, after one filler sentence, or after two filler sentences. The subjects were instructed to respond "yes" when they thought that the test word had appeared in the current paragraph and to respond "no" when they thought that the word had not appeared in the paragraph. After responding to the test word, the subjects continued to read the remaining sentences in the paragraph, if any. All the paragraphs were followed by a yes/no question, to encourage comprehension.

\section{Results and Discussion}

The mean correct RTs for the experimental conditions are displayed in Figure 3. All data were subjected to two ANOVAs, one treating subjects as a random factor and one treating items as a random factor.

The ANOVAs showed that the subjects responded to the target character more rapidly when this character's action occurred simultaneously with the other character's action than when it did not $\left[F 1(1,71)=7.02, M S_{\mathrm{e}}=9,207\right.$, $\left.p<.01 ; F 2(1,35)=3.05, M S_{\mathrm{e}}=9,805, p<.10\right]$. The effect of delay was reliable in the subjects analysis $\left[F 1(2,142)=4.78, M S_{\mathrm{e}}=6,822, p<.01 ; F 2(2,70)=\right.$ $\left.2.22, M S_{\mathrm{e}}=6,392, p>.05\right]$. Finally, the interaction between the factors was not reliable (both $F_{\mathrm{S}}<1$ ).

The mean error rates are presented in Table 2 . In the analysis of the error rates, there were not any reliable differences when characters' actions took place concurrently or at different times (both $F \mathbf{s}<1$ ). The delay effect was not significant $[F(2,142)=1.43]$, and the interaction was not significant either $[F(2,142)=1.01]$. The results of the error rates confirm that RT differences are caused by a speed-accuracy tradeoff.

These results suggest that the temporal relations between characters' actions help organize understanding by governing the accessibility of information from the developing situation model. They also suggest that verbs are important elements in the sentence, providing cues about the status of representational entities by means of aspect information, among other things. This information seems to help readers to select information and to place it appropriately on a foreground-background dimension, and, in fact, they seem to use the temporal information conveyed by verb aspect markers to update the mental model.

\section{GENERAL DISCUSSION}

Taken together, the results of the three experiments replicate those obtained by Glenberg et al. (1987) and

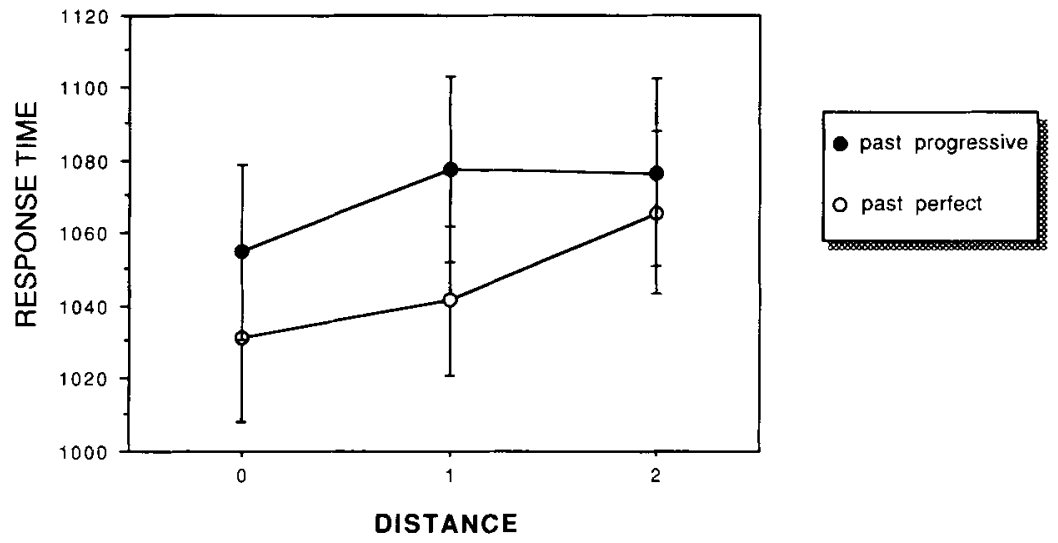

Figure 3. Mean RTs and standard error bars for probe words in the past progressive and past perfect conditions at three delay tests in Experiment 3. 
extend them to show that the association-dissociation effect also occurs in the temporal dimension, suggesting that mental models incorporate temporal information. Probe words (job descriptions and characters) temporally associated with a foregrounded character were more prominent and therefore were responded to more quickly than were probe words that were temporally dissociated from the foregrounded character. Previous work has mainly demonstrated the importance of spatial relations during narrative understanding. Our work shows the importance of temporal relations in organizing narrative understanding by indicating which pieces of information are most prominent. The temporal location of job descriptions and characters with respect to the present moment of the narrative helps to determine their prominence. Our results obtained with probe recognition times agree with those obtained in other investigations that, using different methodologies, have demonstrated that the temporal dimension of situation models is very important (e.g., Anderson et al., 1983; Morrow, 1985a; Zwaan, Langston, \& Graesser, 1995; Zwaan, Magliano, \& Graesser, 1995). Our results also provide converging evidence for the idea that readers construct situational representations that are multidimensional; readers simultaneously monitor more than one situational dimension, one of which is time. So, our results fit both with the structure-building framework (Gernsbacher, 1990) and with the event-indexing model (Zwaan, Langston, \& Graesser, 1995; Zwaan, Magliano, \& Graesser, 1995).

According to Gernsbacher (1990), the goal of comprehension is to build a coherent mental representation or structure. Building such a mental structure involves both laying a foundation and mapping incoming information onto that foundation. This process is facilitated when that incoming information coheres or relates to previous information. Referential, temporal, spatial, and causal coherence are dimensions of situational continuity that facilitate the process of mapping incoming information into an existing structure. However, when the incoming information is less coherent or related, or there is a temporal discontinuity, comprehenders shift and initiate new substructures. Thus, information that maintains temporal continuity is more likely to be mapped onto the developing structure, and, therefore, it will be more accessible than will information temporally discontinuous with the actual time frame. Similarly, the event-indexing model indicates that a reader indexes incoming narrative events on a number of dimensions, time being one of them. Events that share a time index are more strongly connected in the representation than are those that do not. Updating and event indexing (Zwaan, Langston, \& Graesser, 1995; Zwaan, Magliano, \& Graesser, 1995), as well as accessing information that is not indexed in the current time interval (Zwaan, 1996), cause a momentary increase in online processing load. Therefore, both models predict that information that destroys the temporal continuity of the text should be less accessible in the reader's mind than should information that preserves the established time frame, as we have found in our experiments.

Second, our results suggest that verb tense and verb aspect play an important role in the development of a mental representation of a text, affecting the foregrounding of tokens in that representation. A simple change in tense or aspect may affect the accessibility of information at very early stages of processing. Linguistic devices such as tense and aspectual markers are critical for specifying the temporal structure of events (Talmy, 1983) and, therefore, are crucial for understanding narratives, since they specify what readers should focus on in order to construct a model of the narrative world and to update it. Readers understand narratives by constructing a mental model of what the text describes. The representation is a product of knowledge about the objects and actions to which the text refers; it is also a product of linguistic markers and surface organization of the narrative (Garnham, Oakhill, Ehrlich, \& Carreiras, 1995; Johnson-Laird, 1983; Morrow, 1985a; Morrow et al., 1987). It is widely assumed that the entities mentioned in a text are not all equally available, but only a small part of the discourse representation is prominent or active in working memory at any given moment during comprehension. Temporal relations among events that are signaled by tense/aspect markers help indicate which parts of a model are most prominent or active in working memory at each point in comprehension.

Connected discourse and narrative comprehension are partly organized around spatial and protagonist's action coherence. Readers take advantage of spatial and action coherence (De Vega, 1995; O'Brien \& Albrecht, 1992). But, narratives also have temporal coherence, which is marked grammatically (see Zwaan, 1996). Thus, tense/ aspect markers indicate whether situations occur at, prior to, or after the narrative now. Furthermore, they indicate temporal distance from the present - that is, how the situation should be viewed when it is located relative to the narrative time line. For instance, progressive verbs express situations that do not advance the time line, but rather occur at the time of the last mentioned plot event; past perfect verbs express situations prior to a reference point occurring before the present, so the situation is less relevant to the present (Hopper, 1979; Kamp, 1979; Miller \& Johnson-Laird, 1976). Moreover, tense/aspect verb markers are often used in combination with adverbs to express the temporal framework or the narrative and temporal relations between its elements. For example, temporal overlap of two situations is expressed by the words while and as, priority of occurrence is expressed by before, and subsequent occurrence is expressed by after (Miller \& Johnson-Laird, 1976; Talmy, 1978). In our experiments, sentences with present tense (Experiments 1 and 2) and past progressive (Experiment 3) verbs indicate that two events are part of the same ongoing situation, so readers can interpret them within the same time frame. In contrast, sentences with past tense (Experiments 1 and 2) and past perfect (Experiment 3) 
verbs do not allow this possibility, since interpreting the foreground event as currently occurring requires interpreting the backgrounded event as having already occurred.

In conclusion, the present study provides evidence in favor of a multidimensional representation of texts, in which the temporal framework of the text and the temporal relations between pieces of the text play an important role. Furthermore, linguistic devices such as tense/ aspect verb markers help to determine prominence and guide the construction and updating of mental models.

\section{REFERENCES}

Anderson, A., Garrod, S. C., \& Sanford, A. J. (1983). The accessibility of pronominal antecedents as a function of episode shifts in narrative text. Quarterly Journal of Experimental Psychology, 36, 1-12.

Bryant, D. J., TVERSKy, B., \& FrankLin, N. (1992). Internal and external spatial frameworks for representing described scenes. Journal of Memory \& Language 31, 74-98.

Carreiras, M., Garnham, A., Oakhill, J., \& Cain, K. (1996). The use of stereotypical gender information in constructing a mental model. Quarterly Journal of Experimental Psychology, 49A, 639-663.

Carreiras, M., Gernsbacher, M. A., \& Villa, V. (1995). The advantage of first mention in Spanish. Psychonomic Bulletin \& Review, 2, 124-129.

Comrie, B. (1976). Aspect. Cambridge: Cambridge University Press.

Comrie, B. (1985). Tense. Cambridge: Cambridge University Press.

DE VEGA, M. (1995). Backward updating of mental models during continuous reading of narratives. Journal of Experimental Psychology: Learning, Memory, \& Cognition, 21, 373-385.

FERNÁNDEZ, A., \& SAIZ, C. (1989, June). Foregrounding of trait information during text comprehension. Paper presented at the lst European Congress of Psychology, Amsterdam.

Franklin, N., \& TVERSKY, B. (1990). Searching imagined environments. Journal of Experimental Psychology: General, 119, 63-76.

GarnhaM, A. (1981). Mental models as representations of text. Memory \& Cognition, 9, 560-565.

Garnham, A., OAkhill, J., Ehrlich, M. F., \& Carreiras, M. (1995). Representations and processes in the interpretation of pronouns: New evidence from Spanish and French. Journal of Memory \& Language, 34, 41-62.

GERNSBACHER, M. A. (1990). Language comprehension as structure building. Hillsdale, NJ: Erlbaum.

Gernsbacher, M. A., Goldsmith, H. H., \& Robertson, R. R. W. (1992). Do readers mentally represent characters' emotional states? Cognition \& Emotion, 6, 89-111.

Gernsbacher, M. A., \& Hargreaves, D. (1988). Accessing sentence participants: The advantage of first mention. Journal of Memory \& Language, 28, 699-717.

GeRnSBACHER, M. A., \& RoBertson, R. R. W. (1992). Knowledge activation versus sentence mapping when representing fictional characters' emotional states. Language \& Cognitive Processes, 7, 353-371.

GIvóN, T. (1992). Coherence in text vs. coherence in mind: Toward a cognitive model. Unpublished manuscript, University of Oregon.

GlenberG, A. M., MeYer, M., \& Lindem, K. (1987). Mental models contribute to foregrounding during text comprehension. Journal of Memory \& Language, 26, 69-83.

HOPPER, P. (1979). Aspect and foregrounding in discourse. In T. Givón (Ed.), Syntax and semantics: Vol. 12. Discourse and syntax (pp. 213242). New York: Academic Press.

Johnson-Laird, P. N. (1983). Mental models. Cambridge: Cambridge University Press.
KAMP, J. A.W. (1979). Events, instants and temporal reference. In R. Bauerle, U. Egli, \& A. von Stechow (Eds.), Semantics from different points of view. Berlin: Springer-Verlag.

Mani, K., \& Johnson-Laird, P. N. (1982). The mental representation of spatial descriptions. Memory \& Cognition, 10, 181-187.

Miller, G. A., \& Johnson-Laird, P. N. (1976). Language and perception. Cambridge, MA: Harvard University Press, Belknap Press

Morrow, D. G. (1985a). Prepositions and verb aspect in narrative understanding. Journal of Memory \& Language, 24, 390-404.

Morrow, D. G. (1985b). Prominent characters and events organize narrative understanding. Journal of Memory \& Language, 24, 304-319.

Morrow, D. G., Bower, G. H., \& Greenspan, S. E. (1989). Updating situation models during narrative comprehension. Journal of Memory \& Language, 24, 304-319.

Morrow, D. G., Greenspan, S. L., \& Bower, G. H. (1987). Accessibility and situation models in narrative comprehension. Journal of Memory \& Language, 26, 165-187.

O'BRIEN, E. J., \& Al BRECHT, J. E. (1992). Comprehension strategies in the development of a mental model. Journal of Experimental Psychology: Learning, Memory, \& Cognition, 18, 777-784.

RinCK, M., \& Bower, G. H. (1995). Anaphora resolution and the focus of attention in situation models. Journal of Memory \& Language, 34 110-131.

SaIz, C., \& Fernández, A. (1995). Conocimiento e inferencia socia [Knowledge and social influence]. In M. Carretero, J. Almaraz, \& P. Fernández Berrocal (Eds.), Razonamiento y comprensión (pp. 119-131). Madrid: Trotta.

SANFORD, A. J., \& GARROD, S. (1981). Understanding written language. New York: Wiley.

SANFord, A. J., Moar, K., \& Garrod, S. (1988). Proper names as controllers of discourse focus. Language \& Speech, 31, 43-56.

TALMY, L. (1978). Figure and ground in complex sentences. In J. Greenberg, C. Ferguson, \& E. Moravcsik (Eds.), Universals of human language. Stanford, CA: Stanford University Press.

TALMY, L. (1983). How language structures space. In H. Pick \& L. Acredolo (Eds.), Spatial orientation: Theory, research and application (pp. 225-282). New York: Plenum.

TAYLOR, H. A., \& TVERSKY, B. (1992). Spatial mental models derived from survey and route descriptions. Journal of Memory \& Language, 31, 261-292.

van DiJK, T., \& KINTSCH, W. (1983). Strategies of discourse comprehension. San Diego, CA: Academic Press.

ZWAAN, R. A. (1996). Processing narrative time shifts. Journal of Experimental Psychology: Learning, Memory, \& Cognition, 22, 1196-1207.

Zwaan, R. A., Langston, M. C., \& Graesser, A. C. (1995). The construction of situation models in narrative comprehension: An eventindexing model. Psychological Science, 6, 292-297.

ZwaAn, R. A., Magliano, J. P., \& Graesser, A. C. (1995). Dimensions of situation model construction in narrative comprehension. Journal of Experimental Psychology: Learning, Memory, \& Cognition, 21, 386-397.

\section{NOTE}

1. The differentiation between past and present is not reflected simply by the tense of the verb, which is constantly assisted by adverbs in order to make important conceptual time distinctions. The adverbs used in the Spanish texts were ahora and antes. In Table 1, ahora is translated as now. However, the phrase sometime in the past seems to be a more appropriate translation of the word antes than does the corresponding English adverbial form before.

(Manuscript received August 2, 1995; revision accepted for publication June $10,1996$. 